\title{
Alcohol-related family violence in Australia: Secondary data analysis of the National Drug Strategy Household Survey
}

\author{
Breanna Willoughby ${ }^{1}$, Heng Jiang ${ }^{1,2}$, Dan Anderson-Luxford ${ }^{1}$ and Anne-Marie Laslett ${ }^{1,3}$ \\ ${ }^{1}$ Centre for Alcohol Policy Research, La Trobe University, Melbourne, Australia \\ ${ }^{2}$ Centre for Health Equity, School of Population and Global Health, University of Melbourne, Melbourne, Australia \\ ${ }^{3}$ National Drug Research Institute, Curtin University, Perth, Australia
}

\begin{abstract}
Aims: Alcohol is a risk factor for family violence that affects partners, parents, children and other relatives. This study aims to provide estimates of the prevalence of alcohol-related family violence reported in 2016 in Australia across numerous sociodemographic groups.

Methods: This paper presents secondary data analysis of 23,749 respondents (10,840 men, 12,909 women) from the Australian Institute of Health and Welfare's 2016 National Drug Strategy Household Survey (NDSHS). Alcohol-related family violence was measured by self-report as being physically or verbally abused or put in fear from a family member or partner deemed by the victim as under the influence of alcohol. Logistic regression was used to analyse which factors were associated with alcohol-related family violence.

Findings: Analysis revealed that $5.9 \%$ of respondents (7.7\% of women and $4.0 \%$ of men) reported alcohol-related family violence in the past year from either a partner or another family member. Respondents who were women (vs men), within less advantaged (vs more advantaged) socio-economic groups, risky drinkers (vs non-risky drinkers), residing in outer regional areas (vs major cities), holding a diploma (vs high school education) and single with dependents, reported higher overall rates of alcohol-related family violence. In contrast, respondents aged 55+ had significantly lower odds of experiencing alcohol-related family violence than all other age groups.

Conclusions: Alcohol-related family violence was significantly more prevalent amongst respondents in a range of sociodemographic categories. Identification of these groups which are adversely affected by the drinking of family and partners can aid in informing current policy to protect those more vulnerable.
\end{abstract}

\section{Introduction}

Violence is a universally understood act which has been broadly categorised into three overarching groups varying according to whom the act is committed by and upon whom the violence is inflicted. Family violence is a sub-category of interpersonal violence and encompasses the intentional use or threat of violence between family members and intimate partners, typically but not exclusively, taking place in the home (World Health Organization, 2002). Prevention of family violence requires a strong focus on identifying its prevalence and addressing contributing risk factors. Alcohol increases the severity and frequency of family violence (World Health Organization, 2006). Globally, the relationship between alcohol use and increased partner aggression severity has been established in at least 13 culturally diverse countries (Graham et al., 2011). Further research from surveys in six northern European countries has revealed that the reported prevalence of harm due to the drinking of family members and friends ranges from 1428\% (Ramstedt et al., 2015). Similarly in Australia, 16\% of Australians reported being negatively affected by a family member's drinking (Laslett et al., 2011). In a meta-analysis of nine countries, $4.3 \%$ of children were estimated to have been physically hurt or exposed to family violence due to others' drinking in the past year (Laslett et al., 2019). Analysing the proportion of cases that involve alcohol, in New Zealand $37 \%$ of partner offences (referred to as intimate partner violence) and $31 \%$ of offences by people well known to the victim were reported to involve the offender under the influence of alcohol (Connor \& Casswell, 2012).

Correspondence: Breanna Willoughby. Email: B.Willoughby@latrobe.edu.au, Phone number: 0430955541

Financial support: The Centre for Alcohol Policy Research receives core funding from the Foundation for Alcohol Research and Education (FARE). AML is supported by an Australian Research Council Discovery Early Career Researcher Award (DE 190100329). HJ is supported by NHMRC Project Grant (GNT1141325) and ARC Discovery Project (DP200101781). BW and DAL are funded by the Australian Research Council project LP190100698.

Declaration of interest: None

Keywords: alcohol, violence, partners, family, prevalence 
Within Australia, family violence cases are under-reported to police and child protection agencies (Mathews et al., 2013; Wolf et al., 2003); however, in cases that are reported, alcohol consumption is associated with up to $65 \%$ of incidents reported to police and up to $47 \%$ of child protection cases each year ( Laslett al., 2015; Laslett et al., 2021). Due to the high rates of under-reporting of family violence, national surveys have been used to understand how often alcohol is involved in family violence. In an analysis of the 2012 Australian Personal Safety survey (PSS), alcohol and/or drug use was identified as contributory to the most recent incident for $47.2 \%$ of physical threats, and $55.7 \%$ of sexual assaults among women who had experienced violence from a male cohabiting partner (Cox, 2015). Similarly, examination of the 2013 National Drug Strategy Household Survey (NDSHS) determined that 26\% of Australians aged 14 and over reported experiencing an alcohol-related harm in the past year, with women more likely than men to report a current or ex-partner as the perpetrator (Australian Institute of Health and Welfare, 2014).

With alcohol-related family violence considered a major public health issue requiring urgent attention (World Health Organization, 2021), this study aims to estimate the prevalence of alcohol-related family violence within Australian in 2016 across a range of socio-demographic variables.

\section{Methods}

\section{Data and Measures}

This project used data from 23,772 respondents $(10,840$ men, 12,909 women, and 23 respondents who were nonbinary or did not report their gender) aged 12 years and over who completed the 2016 NDSHS.

\section{National Drug Strategy Household Survey}

The NDSHS is a nationally representative Australian survey that collected data utilising a multimode methodology, with participants offered the choice to complete the survey via a paper form, an online form or by telephone interview (response rate $34.7 \%$ ). Full details of the survey methods are detailed elsewhere (Australian Institute of Health and Welfare, 2017). This paper presents the percentages of respondents who reported alcohol-related family violence in the previous 12 months, defined here as harm (physical, verbal, and/or put in fear) from a partner (including current or ex-spouse, -partner, -boyfriend or -girlfriend), or another family member deemed by the respondent as under the influence of, or affected by alcohol. Prevalence estimates and $95 \%$ confidence intervals were derived using complex survey weights supplied by the Australian Institute of Health and Welfare (2017).

\section{Socio-Demographic Variables}

Data estimates are presented by sex (men vs. women), age (examined categorically), socio-economic status (assigned by applying the Socio-Economic Index for Areas [SEIFA] for disadvantage using residential postcode ranging from 1st [most disadvantaged] to 5th [most advantaged]; SEIFA, 2011), remoteness (major cities, inner regional, outer regional), educational level, household composition (single, couple, with or without children) and classification as a risky drinker (five or more drinks in a single episode of drinking at least monthly). Relationship to the person who caused the respondent harm (partner/ex-partner, or another family member, with stranger/friend relationships also reported upon in the Supplementary Material) was also included.

\section{Statistical Analysis}

All data were analysed using STATA (v.14) (StataCorp, 2015). Simple weighted percentages of respondents reporting family violence when the perpetrator was deemed affected by alcohol were calculated for all sociodemographic variables, along with $95 \%$ confidence intervals (CIs), to enable description and comparison of respondents affected by family violence. A logistic regression was also conducted to analyse which socio-demographic variables were associated with the experience of alcohol-related family violence.

\section{Ethics}

La Trobe University Human Ethics Committee approved the secondary analyses (S17-206). The data custodian, AIHW approved use and provided data access.

\section{Results}

Table 1 summarises the prevalence of alcohol-related family violence by relationship type (to the perpetrator) within Australia. Bolded figures designate differences in CIs between intimate partner and family violence prevalence figures in columns. Underlined figures indicate differences between rows within that variable (column), for example, between age groups in reported partner violence. Overall, $5.9 \%$ of respondents reported experiencing violence by someone under the influence of alcohol in the previous 12 months, $3.6 \%$ by a partner and $2.9 \%$ by another family member. Of these respondents, $126(0.57 \%)$ reported experiencing violence by both a partner and another family member. Women reported a significantly higher prevalence of alcohol-related family violence than men across both perpetrator types and overall. This was also observed amongst respondents who were single with dependents and those classified as risky drinkers. Respondents aged 55 years and older reported a significantly lower prevalence overall than all other age groups $(3.7 \%, 95 \%$ CI: $3.3-4.1)$, whereas those with a certificate or diploma had a significantly higher prevalence of alcohol-related family violence than those with other education levels. Participants from the most disadvantaged socio-economic group reported a significantly higher percentage of violence from intoxicated partners and family members $(6.4 \%, 95 \%$ CI: $5.6-7.4 \%)$ than those from the most advantaged socio-economic group $(4.8 \%, 95 \%$ CI: $4.1-5.5 \%)$, with no significant differences in partner or family violence between other SEIFA quintiles. Moreover, prevalence of violence from another family member and overall was significantly greater in outer regional areas compared to major cities.

Further analysis regarding types of alcohol-related family violence were conducted on the subset of respondents $(\mathrm{n}=$ 4,929) who reported harm from someone else's drinking in the past 12 months. Prevalence rates were compared by respondent relationship to the offender across gender and age groups. Findings can be found in Supplementary Material, Tables S.1 and S.2. 
Table 1

Prevalence of Violence from Others' Drinking from a Partner, Another Family Member and Overall, in the Last 12 Months

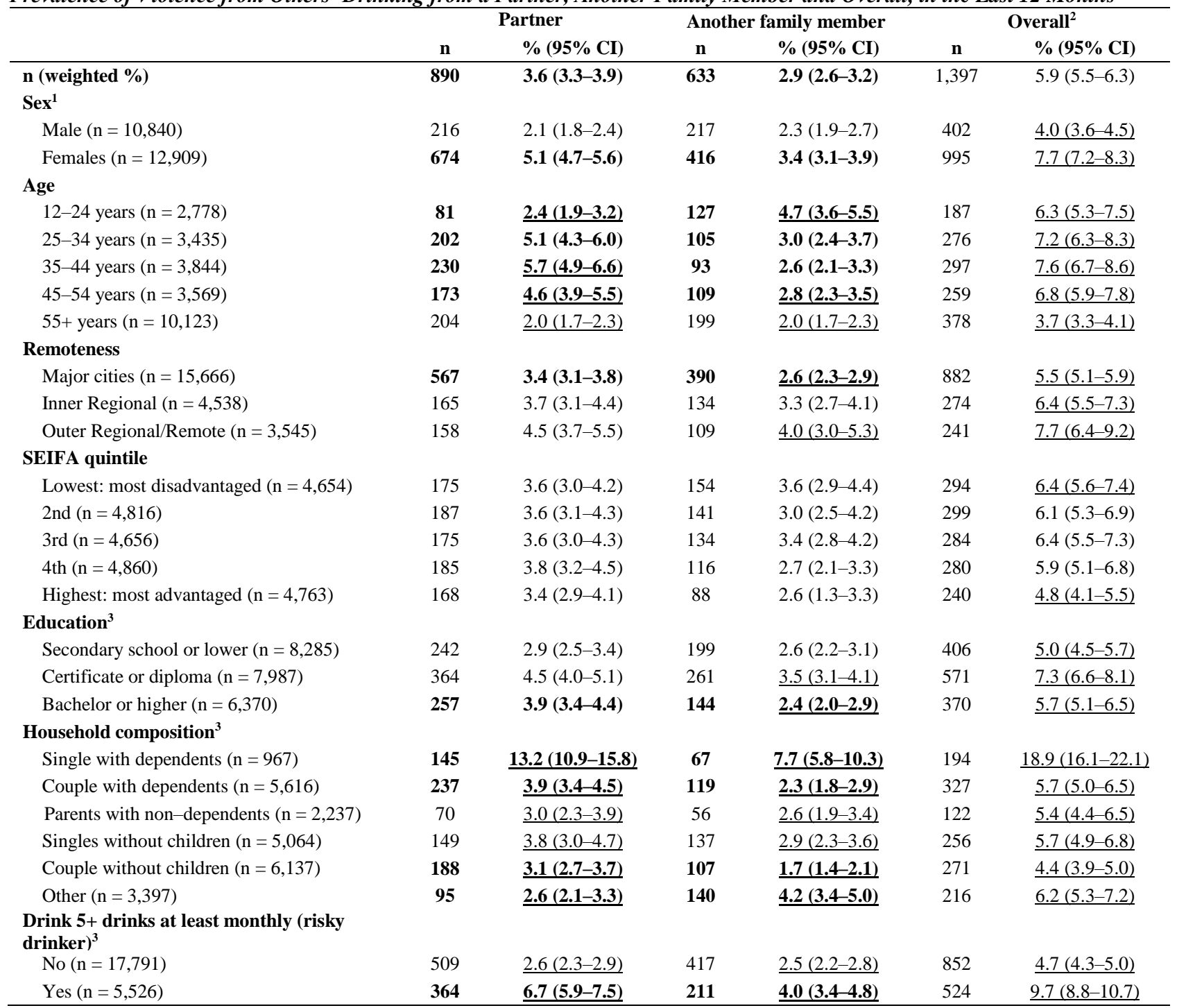

Note. Non-overlapping confidence intervals are conservative estimates of significant difference at $\mathrm{p}<0.05$ level. Underlined figures indicate differences between rows within that variable, for example, between age groups.

${ }^{1} \mathrm{n}=23,749$. Due to small numbers of participants selecting 'non-binary' gender or not reporting their gender, only women and men are included in the analysis.

${ }^{2}$ This is a multi-selection question, of which $126(0.57 \%)$ respondents reported being harmed both by partner and another family member, who were under the influence of alcohol.

${ }^{3}$ Missing values were found in education (missing $=1,129$ ), household composition (missing $=331$ ), and participants' own risky drinking (missing $=432$ ) variables; the missing values were less than $5 \%$ of the total and considered unlikely to affect the results of our analyses

Results of a logistic regression analysing the association of selected socio-demographic variables with the experience of alcohol-related family violence are presented in Table 2. Females and risky drinkers had significantly higher odds of experiencing each individual type of violence, as well as any violence, compared to men and non-risky drinkers. Respondents holding a certificate or diploma and residing in outer regional areas were at significantly higher odds of reporting any violence and verbal abuse compared with those at secondary school education level or living within a major city. Interestingly, residents in outer regional areas had significantly lower odds of experiencing physical abuse than if living in a major city $(\mathrm{OR}=0.59, \mathrm{p}<.01)$. Respondents aged 55 years or older had significantly lower odds of experiencing any alcohol-related family violence compared to those aged 12 to 24 years, with this also observed in respondents between 45 and 54 years and experiencing being put in fear $(\mathrm{OR}=0.62, \mathrm{p}=0.03)$. Moreover, respondents within the highest SEIFA quintile had significantly lower odds of experiencing fear $(\mathrm{OR}=0.73, \mathrm{p}=0.05)$ and/or any violence $(\mathrm{OR}=0.79, \mathrm{p}=0.04)$ than those in the lowest quintile; however there were no differences across SEIFA quintiles regarding physical or verbal abuse. Interestingly, all household compositions had significantly lower odds of experiencing alcohol-related family violence compared to single respondents with dependents. 
Table 2

Odds of Experiencing Any and Each of the Three Types of Alcohol-Related Violence due to a Family Member's Drinking

\begin{tabular}{|c|c|c|c|c|c|c|c|c|}
\hline & \multicolumn{2}{|c|}{ Any violence } & \multicolumn{2}{|c|}{ Verbal abuse } & \multicolumn{2}{|c|}{ Physical abuse } & \multicolumn{2}{|c|}{ Fear } \\
\hline & OR & $95 \% \mathrm{CI}$ & OR & $95 \% \mathrm{CI}$ & OR & $95 \% \mathrm{CI}$ & OR & $95 \% \mathrm{CI}$ \\
\hline \multicolumn{9}{|l|}{ Sex } \\
\hline Male (Ref) & 1.00 & - & 1.00 & - & 1.00 & - & 1.00 & - \\
\hline Females & 2.36 & 2.01-2.77 & 2.20 & $1.86-2.60$ & 2.06 & $1.57-2.69$ & 3.31 & $2.55-4.31$ \\
\hline \multicolumn{9}{|l|}{ Age } \\
\hline 12-24 years (Ref) & 1.00 & - & 1.00 & - & 1.00 & - & 1.00 & - \\
\hline $25-34$ years & 1.01 & $0.74-1.37$ & 1.10 & $0.79-1.52$ & 0.92 & $0.56-1.49$ & 0.77 & $0.52-1.15$ \\
\hline $35-44$ years & 1.09 & $0.78-1.51$ & 1.16 & $0.81-1.65$ & 1.07 & $0.62-1.85$ & 0.85 & $0.55-1.31$ \\
\hline $45-54$ years & 0.96 & $0.69-1.34$ & 1.03 & $0.72-1.48$ & 0.75 & $0.43-1.30$ & 0.62 & $0.40-0.96$ \\
\hline $55+$ years & 0.64 & $0.47-0.88$ & 0.71 & $0.51-0.99$ & 0.41 & $0.25-0.67$ & 0.31 & $0.20-0.46$ \\
\hline \multicolumn{9}{|l|}{ Remoteness } \\
\hline Major cities (Ref) & 1.00 & - & 1.00 & - & 1.00 & - & 1.00 & - \\
\hline Inner Regional & 1.08 & $0.90-1.30$ & 1.01 & $0.84-1.22$ & 0.88 & $0.64-1.21$ & 1.06 & $0.83-1.37$ \\
\hline Outer Regional/Remote & 1.31 & $1.04-1.64$ & 1.22 & $0.96-1.55$ & 0.59 & $1.13-2.24$ & 1.35 & $0.98-1.86$ \\
\hline \multicolumn{9}{|l|}{ SEIFA quintile } \\
\hline Lowest: most disadvantaged (Ref) & 1.00 & - & 1.00 & - & 1.00 & - & 1.00 & - \\
\hline 2nd & 0.94 & $0.76-1.17$ & 0.97 & $0.77-1.21$ & 0.81 & $0.57-1.14$ & 0.91 & $0.68-1.23$ \\
\hline $3 \mathrm{rd}$ & 0.97 & $0.78-1.21$ & 0.96 & $0.76-1.21$ & 0.96 & $0.68-1.36$ & 1.02 & $0.75-1.38$ \\
\hline 4 th & 0.91 & $0.72-1.15$ & 0.94 & $0.74-1.20$ & 0.80 & $0.55-1.17$ & 0.76 & $0.54-1.06$ \\
\hline Highest: most advantaged & 0.79 & $0.62-0.99$ & 0.80 & $0.63-1.01$ & 0.75 & $0.52-1.08$ & 0.73 & $0.53-1.00$ \\
\hline \multicolumn{9}{|l|}{ Education $^{1}$} \\
\hline Secondary school or lower (Ref) & 1.00 & - & 1.00 & - & 1.00 & - & 1.00 & - \\
\hline Certificate or diploma & 1.33 & $1.12-1.58$ & 1.38 & $1.15-1.66$ & 1.30 & $0.99-1.72$ & 1.26 & $0.99-1.62$ \\
\hline Bachelor or higher & 1.13 & $0.93-1.37$ & 1.10 & $0.90-1.35$ & 0.89 & $0.64-1.23$ & 1.13 & $0.86-1.49$ \\
\hline \multicolumn{9}{|l|}{ Household composition $^{1}$} \\
\hline Single with dependents (Ref) & 1.00 & - & 1.00 & - & 1.00 & - & 1.00 & - \\
\hline Couple with dependents & 0.37 & $0.28-0.47$ & 0.34 & $0.27-0.44$ & 0.31 & $0.21-0.46$ & 0.35 & $0.25-0.50$ \\
\hline Parents with non-dependents & 0.45 & $0.33-0.61$ & 0.42 & $0.31-0.58$ & 0.51 & $0.32-0.82$ & 0.49 & $0.31-0.76$ \\
\hline Singles without children & 0.40 & $0.30-0.53$ & 0.36 & $0.27-0.49$ & 0.53 & $0.35-0.81$ & 0.59 & $0.41-0.85$ \\
\hline Couple without children & 0.36 & $0.27-0.46$ & 0.33 & $0.25-0.43$ & 0.29 & $0.19-0.44$ & 0.38 & $0.26-0.54$ \\
\hline Other & 0.44 & $0.32-0.60$ & 0.40 & $0.29-0.56$ & 0.41 & $0.25-0.68$ & 0.43 & $0.29-0.65$ \\
\hline \multicolumn{9}{|l|}{$\begin{array}{l}\text { Drink 5+ drinks at least monthly (risky } \\
\text { drinker) }^{1}\end{array}$} \\
\hline No (Ref) & 1.00 & - & 1.00 & - & 1.00 & - & 1.00 & - \\
\hline Yes & 2.37 & $2.03-2.76$ & 2.38 & 2.02-2.80 & 2.86 & 2.23-3.67 & 2.16 & 1.73-2.68 \\
\hline
\end{tabular}

Note. $\mathrm{N}=23,749$. Ref $=1.00$

${ }^{1}$ Missing values were coded as missing sub-categories in education, housing composition and risky drinker variables. The regression results of these separate missing value categories are not presented in this table.

\section{Discussion}

The present study aimed to estimate the overall prevalence of violence from partners' and other family members' drinking in 2016 across different socio-demographic variables in Australia. Overall, respondents who were women, residing in an outer regional area and in the most disadvantaged quintile reported experiencing both a significantly higher prevalence and odds of alcohol-related family violence than respondents who were male, resided in a major city and in the most advantaged socio-economic group. Single respondents living with dependents were also at increased risk of alcohol-related family violence, compared to all other household compositions. Consistent with previous findings, gender was associated with alcoholrelated violence (Friesen et al., 2021; Taft et al., 2019). Economic disparities also emerged in line with broader research and suggested that poorer groups tended to experience more alcohol-related violence than wealthier cohorts, even after accounting for differences in consumption (Bryant \& Lightowlers, 2021; Wood \& Bellis,
2017). Moreover, the finding that younger age groups had a significantly higher prevalence and odds of experiencing alcohol-related family violence than respondents aged 55 years and older, aligns with analyses of Australian data by Miller et al. (2016).

Interestingly, respondents holding a certificate or diploma had significantly higher odds of experiencing alcoholrelated family violence than those having an education level of secondary school or lower. Previous findings indicate lower education levels as associated with higher prevalence rates (Curtis et al., 2019), conflicting with the current study. On the other hand, classification as a risky drinker and experiencing both a significantly higher prevalence and odds of alcohol-related family violence is consistent with research discerning hazardous drinking and heavy episodic drinking by both the victim and offender, as associated with higher violence rates both in Australia and internationally (Curtis et al., 2019; Sundin et al., 2021).

This study was not without its limitations. Despite the NDSHS being the largest nationally representative sample 
on alcohol and drug use and harm, small numbers in subgroups and no translation into other languages (e.g., Mandarin, Arabic, Cantonese, Vietnamese, etc.) preclude analysis of harm in culturally and linguistically diverse (and other smaller) groups. Asking respondents to retrospectively report on their experience of alcohol-related family violence presents the potential for issues regarding recall accuracy and stigma which likely produced under-reporting (Emery, 2010; Greenfield \& Kerr, 2008). Moreover, as the survey is by definition a "household survey", individuals without a fixed home were excluded, and it is known that this group is at greater risk of violence (Larney et al., 2009).

\section{Conclusion}

Alcohol-related family violence was significantly more prevalent amongst respondents who were women, those in the most disadvantaged socio-economic quintile, residing in outer regional areas, single with dependents and classified as risky drinkers. Persons aged 55 years and older reported a significantly lower prevalence of violence from the drinking of partners and other family members than younger respondents. Furthermore, holders of a certificate or diploma experienced a higher prevalence of violence than those with a lower education level. These same significant differences across the socio-demographic variables were also observed with regard to the odds of experiencing the differing types of alcohol-related family violence.

These results highlight the groups most likely to be negatively affected by partners' and other family members' drinking and thus inform our understanding of alcoholrelated harm in families. Overall, the research findings support the identification of alcohol as a risk factor for family violence and suggest the need for current policy to address the socio-economic disparities evident in the experience of alcohol-related family violence.

\section{References}

Australian Institute of Health and Welfare. (2014). National Drug Strategy Household Survey detailed report 2013. (Cat. no: PHE 183). https://www.aihw.gov.au/reports/illicit-useof-drugs/2013-ndshs-detailed/summary

Australian Institute of Health and Welfare. (2017). National Drug Strategy Household Survey Detailed Findings. (Cat. no: PHE 214). https://www.aihw.gov.au/getmedia/15db8c15-7062-4cdebfa4-3c2079f30af3/aihw-phe-214.pdf.aspx?inline=true

Bryant, L., \& Lightowlers, C. (2021). The socioeconomic distribution of alcohol-related violence in England and Wales. PLoS ONE, 16(2), 1-18. https://doi.org/10.1371/journal.pone.0243206

Connor, J., \& Casswell, S. (2012). Alcohol-related harm to others in New Zealand: Evidence of the burden and gaps in knowledge. The New Zealand Medical Journal, 125(1360), $11-27$.

Cox , P. (2015). Violence against women in Australia: Additional analysis of the Australian Bureau of Statistics' Personal Safety Survey, 2012. Australia's National Research Organisation for Women's Safety Limited (ANROWS). https://apo.org.au/node/58140

Curtis, A., Vandenberg, B., Mayshak, R., Coomber, K., Hyder, S., Walker, A., Liknaitzky, P., \& Miller, P. G. (2019). Alcohol use in family, domestic and other violence: Findings from a cross-sectional survey of the Australian population. Drug and Alcohol Review, 38(4), 349-358. https://doi.org/10.1111/dar.12925

Emery, C. R. (2010). Examining an extension of Johnson's hypothesis: Is male perpetrated intimate partner violence more underreported than female violence? Journal of Family Violence, 25(2), 173-181. https://doi.org/10.1007/s10896-009-9281-0

Friesen, E. L., Bailey, J., Hyett, S., Sedighi, S., de Snoo, M. L., Williams, K., Barry, R., Erickson, A., Foroutan, F., Selby, P., Rosella, L., \& Kurdyak, P. (2021). Hazardous alcohol use and alcohol-related harm in rural and remote communities: A scoping review. The Lancet. Public Health. https://doi.org/10.1016/S2468-2667(21)00159-6

Graham, K., Bernards, S., Wilsnack, S. C., \& Gmel, G. (2011). Alcohol may not cause partner violence but it seems to make it worse: A cross national comparison of the relationship between alcohol and severity of partner violence. Journal of Interpersonal Violence, 26(8), 1503-1523. https://doi.org/10.1177/0886260510370596

Greenfield, T. K., \& Kerr, W. C. (2008). Alcohol measurement methodology in epidemiology: Recent advances and opportunities. Addiction, 103(7), 1082-1099. https://doi.org/10.1111/j.1360-0443.2008.02197.x

Larney, S., Conroy, E., Mills, K. L., Burns, L., \& Teesson, M. (2009). Factors associated with violent victimisation among homeless adults in Sydney, Australia. Australian and New Zealand Journal of Public Health,33(4), 347-351. https://doi.org/10.1111/j.1753-6405.2009.00406.x

Laslett, A.-M., Anderson-Luxford, D., \& Crane, M (2021). Joint Submission by the Foundation for Alcohol Research and Education (FARE) and the Centre for Alcohol Policy Research (CAPR), La Trobe University to the Inquiry into family, domestic and sexual violence by the House Standing Committee on Social Policy and Legal Affairs, Canberra, Australia. Submission number 125. (31 July 2020). https://www.aph.gov.au/Parliamentary_Business/Committe es/House/Social_Policy_and_Legal_Affairs/Familyviolenc e/Submissions/

Laslett, A.-M., Mugavin, J., Jiang, H., Manton, E., Callinan, S., Maclean, S., \& Room, R. (2015). The hidden harm: Alcohol's impact on children and families, (ISBN: 978-09924978-4-2). https://fare.org.au/wp-content/uploads/01ALCOHOLS-IMPACT-ON-CHILDREN-ANDFAMILIES-web.pdf

Laslett, A. -M., Room, R., Ferris, J., Wilkinson, C., Livingston, M., \& Mugavin, J. (2011). Surveying the range and magnitude of alcohol's harm to others in Australia. Addiction, 106(9), 1603-1611. https://doi.org/10.1111/j.1360-0443.2011.03445.x

Laslett, A.-M., Stanesby, O., Graham, K., Callinan, S., KarrikerJaffe, K.J., Wilsnack, S., Kuntsche, S., Waleewong, O., Greenfield, T.K., Gmel, G., Florenzano, R., Hettige, S., Siengsounthone, L., Wilson I., Taft, A., \& Room, R. (2019). Children's experience of physical harms and exposure to family violence from others' drinking in nine societies. Addiction Research and Theory, 28(4), 354-364, https://doi.org/10.1080/16066359.2019.1704272

Mathews, S., Abrahams, N., Jewkes, R., \& Martin, L. J. (2013). Underreporting child abuse deaths: Experiences from a national study on child homicide. South African Medical Journal, 103(3),

132-133. https://doi.org/10.7196/SAMJ.6724

Miller, P., Cox, E., Costa, B., Mayshak, R., Walker, A., Hyder, S., Tonner, L., \& Day, A. (2016). Alcohol/drug-involved family violence in Australia (ADIVA): Key findings. https://www.aic.gov.au/publications/ndlerfmonograph/ndle rfmonograph68 
Ramstedt, M., w, E., Moan, I. S., Storvoll, E. E., Lund, I. O., Bloomfield, K., Hope, A., Kristjánsson, S., \& Tigerstedt, C. (2015). Harm experienced from the heavy drinking of family and friends in the general population: A comparative study of six Northern European countries. Substance Abuse: Research and Treatment,9s2, SART.S23746. https://doi.org/10.4137/SART.S23746

Australian Institute of Health and Welfare (2017). National Drug Strategy Household Survey 2016: Detailed findings. Drug Statistics series no. 31. Cat. no. PHE 214. Canberra: AIHW. https://www.aihw.gov.au/getmedia/15db8c157062-4cde-bfa4-3c2079f30af3/21028a.pdf.aspx?inline=true

Sundin, E., Landberg, J., Galanti, M. R., Room, R., \& Ramstedt, M. (2021). Country-level heavy episodic drinking and individual-level experiences of harm from others' drinkingrelated aggression in 19 European countries. European Addiction Research, 1-9. https://www.karger.com/Article/FullText/520079\#

Taft, A., Wilson, I., Laslett, A. -M., \& Kuntsche, S. (2019). Pathways to responding and preventing alcohol-related violence against women: Why a gendered approach matters. Australian and New Zealand Journal of Public Health, 43(6), 516-518. http://doi.org/10.1111/17536405.12943

Wolf, M. E., Ly, U., Hobart, M. A., \& Kernic, M. A. (2003). Barriers to seeking police help for intimate partner violence. Journal of Family Violence, 18(2), 121-129. https://doi.org/10.1023/A:1022893231951

Wood, S., \& Bellis, M. (2017). Socio-economic inequalities in alcohol consumption and harm: Evidence for effective interventions and policy across EU countries. Brussels: European Commission. https://ec.europa.eu/health/sites/default/files/social_determi nants/docs/hepp_screport_alcohol_en.pdf

World Health Organization. (2002). Violence - a global public health problem. In E. Krug., L. Dahlberg., J. Mercy., A. Zwi., \& R. Lozano (Eds.), World report on violence and health, (pp. 1-19). World Health Organization. https://apps.who.int/iris/bitstream/handle/10665/42495/924 1545615_eng.pdf

World Health Organization. (2006). Interpersonal violence and alcohol. https://www.who.int/violence_injury_prevention/violence/ world_report/factsheets/pb_violencealcohol.pdf

World Health Organization (2021, March 9). Violence against women: Key facts. https://www.who.int/news-room/factsheets/detail/violence-against-women 